\title{
Promoting reproductive health services in rural communities in Honduras
}

Irma Mendoza

Population Council

Ricardo Vernon

Population Council

Follow this and additional works at: https://knowledgecommons.popcouncil.org/departments_sbsr-rh

Part of the Demography, Population, and Ecology Commons, International Public Health Commons, Maternal and Child Health Commons, and the Public Health Education and Promotion Commons How does access to this work benefit you? Let us know!

\section{Recommended Citation}

Mendoza, Irma and Ricardo Vernon. 2001. "Promoting reproductive health services in rural communities in Honduras," FRONTIERS Final Report. Washington, DC: Population Council. 


\title{
PROMOTING REPRODUCTIVE HEALTH SERVICES IN RURAL COMMUNITIES IN HONDURAS
}

\author{
Irma Mendoza \\ Ricardo Vernon \\ POPULATION COUNCIL \\ FRONTIERS IN REPRODUCTIVE HEALTH
}

June 15, 2001

This is a sub-study conducted as part of project "Expansion of the Role of Nurse Auxiliaries in the Provision of Family Planning Services: Phase 2." April 1999 - June 2001. This study was funded by the U.S. AGENCY FOR INTERNATIONAL DEVELOPMENT (USAID) under the terms of Cooperative Agreement Number HRNA-00-98-00012-00 and Subproject number 5801-13008 424. The opinions expressed herein are those of the authors and do not necessarily reflect the view of USAID. 


\section{SUMMARY}

Using the results of a previous operations research study, the Ministry of Health of Honduras recently changed the National Women's Health Service Delivery Guidelines to explicitly authorize nurse auxiliaries to insert IUDs, deliver Depo-Provera and take Pap smears. These services are new to the rural communities served by rural health centers (RHCs).

The objective of this project was to test whether the demand for these newly introduced services would increase at the rural health centers (RHCs) if a promotional brochure was distributed in the surrounding communities by the RHC's clients. The nurse auxiliaries gave ten-minute talks at the RHCs and asked clinic clients to distribute the brochures among potentially interested friends in their communities. Twelve rural health centers (RHCs) participated in the study: six in the experimental group where brochures were distributed, and six in the control group, where no special activity was conducted. The twelve RHCs were randomly selected from 180 in which the nurse auxiliaries had been trained in the provision of these services as part of a FRONTIERS intermediate result 2 project. To assess the intervention, we compared the services delivered three months before and three months after the intervention in both the experimental and the control groups.

New IUD users increased from 2.8 to 4.5 per month in the experimental group, while in the control group they decreased from 1.4 to 0.9 . New injectable users increased an average of 1.8 users per month in the experimental group, compared to 0.6 new users in the control group. Finally, Pap smears increased by 1.6 samples per month in the experimental group, and decreased by 0.1 samples per month in the control group. However, mean tests showed that the only statistically significant differences in both groups were the increases in the number of injectable users. A t-test to compare the service delivery differences between the experimental and the control groups found that the experimental group had significantly higher change rates than the control group.

We recommend the use of this strategy for all sites where RHCs have recently introduced the three new services. It is estimated that in the expansion period, the cost per additional user generated by the strategy would only be about US $\$ 0.13$. 


\section{CONTENTS}

Acknowledgements..........................................................

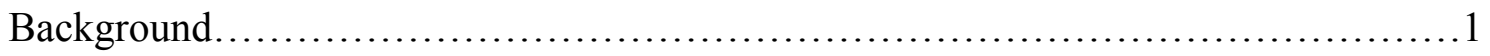

Problem Statement.... ...................................................

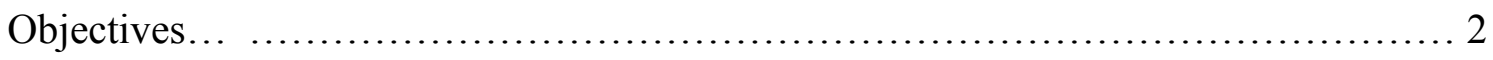

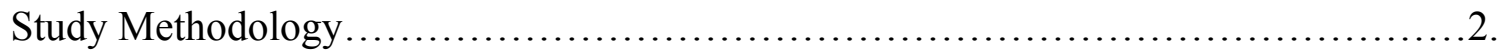

Major Findings........................................................ 3

Utilization............................................................. 5

Conclusions and Recommendations........................................ 6

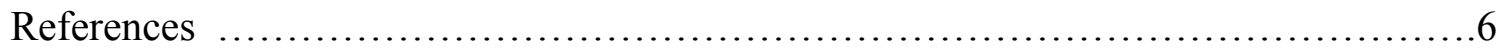

Appendix: Promotional Brochure ........................................... 


\section{LIST OF TABLES}

Table 1: $\quad$ Number of Services Delivered Three Months Before and After the Intervention, by Experimental Group and Type of Service

Table 2: $\quad$ Monthly Average of Delivered Services, by Experimental Group, and Type of Service

Table 3: $\quad$ Average Difference in the Delivery of Services between the Periods Before and After, by Experimental Group and Type of Service

\section{LIST OF APPENDICES}

Appendix 1: Brochure promoting the new services

\section{ABBREVIATIONS}

MHC: $\quad$ Health center with physician and dentist (or CESAMO, as commonly referred to in Honduras)

RHC: $\quad$ Rural health center (Centro de Salud Rural, or CESAR, as referred to in Honduras)

IUD: $\quad$ Intrauterine Device

DMPA: DepoProvera

MOH: $\quad$ Ministry of Health of Honduras

\section{ACKNOWLEDGEMENTS}

We wish to thank Dr. Jorge Meléndez, Head of the Maternal-Child Department, and Dr. Ivo Flores, Head of Attention to Women, for their constant support and magnificent guidance in developing this project. Also, Julio César Arita, Carlos Alfonso Bennaton, Efraín Aguilar, Rafael Mejía Borjes, Heads of Regions 1,3, 5 y 6, where project activities took place.

The USAID Mission in Honduras partially financed the activities for this project. We gratefully acknowledge John Rogosh, Richard Montieth, Meri Sinnit, and Angel Coca for this support.

Above all, we wish to thank the nurse auxiliaries who carried out the activities and collected the information for evaluating the activities. 


\section{BACKGROUND}

Currently, $50 \%$ of married 1 women in Honduras are using a contraceptive method. However, there are marked differences between urban $(66.9 \%)$ and rural areas (40.4\%)2. Rural Health Centers (RHCs) are the most accessible health services for women in rural areas in Honduras. RHCs are staffed by nurse auxiliaries, who attain this degree by completing a two-year technical course after junior high school.

Until recently, one of the main problems faced by women in rural areas was that long-term contraceptive methods were not easily accessible, since service delivery guidelines did not authorize nurse auxiliaries to insert IUDs and provide Depo-Provera. Therefore, INOPAL III conducted a project to determine if nurse auxiliaries could successfully provide these services, as well as take Pap smears3. Results showed that most of the 60 nurses who participated in the study delivered quality services in terms of information given to users, compliance with service delivery guidelines, and follow-up with users. Study participants inserted a total of 2,030 IUDs. Furthermore, a study that took place in five RHCs showed that the costs per new IUD user varied from US\$2.90 to $\$ 18.60$, while costs for each cytology varied from $\$ 1.50$ to $\$ 9.40$. Given this experience, the MOH changed the Women's Health Service Delivery Guidelines4 and authorized nurse auxiliaries to provide these services.

\section{PROBLEM STATEMENT}

The new service delivery guidelines authorize nurse auxiliaries to insert IUDs, provide Depo-Provera to new users, and take Pap smears. In practical terms, these three services are new to the rural areas, and thus, there is a need to promote the services to increase their acceptance. Because the $\mathrm{MOH}$ has a very restricted budget, the promotion strategy should not be expensive and yet, should reach the small rural communities that surround the RHC. Because the nurse auxiliary is the only service agent at the RHC, the promotion strategy should not require her to leave the health center.

\footnotetext{
1 The term 'married women' will be used synonymously with 'married or in union'.

2 Secretaría de Salud de Honduras, Ashonplafa, CDC y USAID. 1997. Honduras: Encuesta Nacional de Epidemiología y Salud Familiar 1996. Tegucigalpa, Honduras.

3 See Villanueva, Yanira L. Hernández, I. Mendoza y R. Lundgren. 1998. Expansión del Rol de las Auxiliares de Enfermería en el ofrecimiento de servicios de planificación familiar y en la toma de Citologías Vaginales. INOPAL III Informe Final. Tegucigalpa, Honduras, Population Council 4 Secretaría de Salud de Honduras. Departamento de Salud Materno Infantil.1999. Manual de Normas y Procedimientos de Atención Integral a la Mujer. Secretaría de Salud, Tegucigalpa, Honduras, Septiembre.
} 


\section{OBJECTIVES}

The purpose of this project was to test the effect of promoting the IUD, DepoProvera and Pap smears by means of a simple brochure that nurse auxiliaries gave to women attending the RHC, who in turn were encouraged to distribute them among their friends and neighbors in their communities.

\section{STUDY METHODOLOGY}

The most common health education activities conducted by nurse auxiliaries are talks to groups of women (either at the health center or in the communities) and household visits. Printed materials are only used when the central department of a given health program in Tegucigalpa makes them available, and usually they are used as a counseling tool, rather than as a means to promote services. The new services could be promoted by means of a simple flyer explaining what the new services are and who could benefit from them, and by distributing them to the communities via the clients who attend the RHCs.

\section{Design}

To conduct the study, 12 nurse auxiliaries who had been trained in the delivery of the new services, were randomly selected and assigned to either an experimental or a control group. The six nurse auxiliaries from the experimental group gave a daily tenminute talk about the new services available to women attending the RHC. In addition, the auxiliaries gave five brochures promoting the new services to each woman, and asked them to distribute the flyers among friends and neighbors who might be interested in the services. Each nurse auxiliary received 500 brochures. Appendix 1 shows a copy of the brochure. In the control group, no interventions took place other than those which the $\mathrm{MOH}$ staff ordinarily carries out.

To evaluate the effects of the intervention, we used an experimental pre-post evaluation design with a control group:

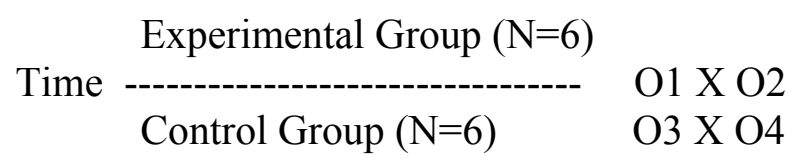

Where $\mathrm{X}$ represents the daily talks and distribution of the brochure, O1 and $\mathrm{O} 3$ represent measurement of the dependent variables during the three months before the intervention in both the experimental and the control group, and $\mathrm{O} 2$ and $\mathrm{O} 4$ represent 
measurement of the dependent variables during the three months after the intervention in both groups. The dependent variables were: 1) number of new IUD users; 2) number of new and subsequent DMPA users visits; and 3) number of Pap smears taken per month.

The hypothesis was that the demand for new services would increase more in the experimental group - where the services were promoted - than in the control group.

The information on the number of insertions, Depo-Provera injections and Pap smears was obtained from service statistics reports and from the books that the nurses use to record their daily activities. The cost-effectiveness of the intervention was estimated by dividing the total number of procedures performed by the total costs of the training (trips and per-diem) and the costs of printing and distributing the brochures. The differences between insertions and Pap smears were analyzed through t-tests using SPSS.

\section{MAJOR FINDINGS}

Table 1 shows that in the RHCs where nurse auxiliaries gave daily ten-minute talks and distributed brochures, the number of services provided increased from 631 to 767 $(22 \%)$. The corresponding increase at the RHCs where no promotion took place was only $12 \%$ (from 193 to 216 services).

\section{Table 1}

\section{Number of Services Delivered During the Three Months Before and After the Intervention, by Experimental Group and Type of Service}

\begin{tabular}{|l|c|c|c|c|c|c|}
\hline \multirow{2}{*}{ SERVICES } & \multicolumn{3}{c|}{$\begin{array}{c}\text { EXPERIMENTAL GROUP } \\
(\mathrm{N}=6)\end{array}$} & \multicolumn{3}{c|}{$\begin{array}{c}\text { CONTROL GROUP } \\
(\mathrm{N}=6)\end{array}$} \\
\cline { 2 - 7 } & BEFORE & AFTER & $\begin{array}{c}\text { PERCENT } \\
\text { CHANGE }\end{array}$ & BEFORE & AFTER & $\begin{array}{c}\text { PERCENT } \\
\text { CHANGE }\end{array}$ \\
\hline IUD Insertion & 50 & 75 & $50 \%$ & 26 & 15 & $-(42 \%)$ \\
\hline IUD Check-up & 84 & 113 & $34 \%$ & 8 & 15 & $87 \%$ \\
\hline New Depo-Provera & 89 & 121 & $36 \%$ & 53 & 63 & $19 \%$ \\
\hline $\begin{array}{l}\text { Depo-Provera } \\
\text { Check-up }\end{array}$ & 71 & 93 & $31 \%$ & 53 & 71 & $34 \%$ \\
\hline Pap Smears & 337 & 365 & $8 \%$ & 53 & 51 & $-(4 \%)$ \\
\hline TOTAL & 631 & 767 & $22 \%$ & 193 & 216 & $12 \%$ \\
\hline
\end{tabular}

Table 1 also shows that the number of IUD insertions at experimental RHCs increased from 50 to 75, while at the control group RHCs they decreased from 26 to 16. The relative increase in the number of Depo-Provera users at the experimental group units was $36 \%$, versus $19 \%$ at the control group units. And while nurse auxiliaries in the experimental group took $22 \%$ more Pap smears after the intervention, those at the control group took $4 \%$ less than before the intervention. The total number of new users of long- 
term contraceptive methods (IUD and DMPA) increased by $41 \%$ in the experimental group and decreased by $2 \%$ in the control group.

Table 2 shows the average monthly number of services provided in the experimental and in the control group health centers in the three pre-intervention months and the three post-intervention months. We first compared the mean number of services provided in the three months before the intervention and found that the health centers in the experimental group had had a statistically significant higher output even before the intervention. Since the relative number of services provided increased more in the experimental sites, it was not surprising to observe significant differences in the mean number of services provided in the experimental and control groups after the intervention.

A second analysis consisted of observing whether there were significant changes in the productivity of each group between the pre and post intervention periods. In general terms, there were more substantial increases in the experimental group than in the control group. However, t-tests showed that the only statistically significant increase was the number of new injectable users in the experimental group, and of new and follow-up injectable visits in the control group.

Table 2

Monthly Average of Delivered Services, by Experimental Group and Type of Service

\begin{tabular}{|l|c|c|c|c|c|c|}
\hline \multirow{2}{*}{ SERVICE } & \multicolumn{6}{|c|}{ GROUP } \\
\cline { 2 - 7 } & \multicolumn{3}{|c|}{ EXPERIMENTAL } & \multicolumn{3}{c|}{ CONTROL } \\
\cline { 2 - 7 } & BEFORE & AFTER & TOTAL & BEFORE & AFTER & TOTAL \\
\hline Cytology & 18.7 & 20.3 & 19.5 & 2.9 & 2.8 & 2.8 \\
\hline IUD Insertion & 4.7 & 6.3 & 5.5 & 0.4 & 0.8 & 0.6 \\
\hline IUD Check-up & 2.8 & 4.2 & 3.5 & 1.4 & 0.9 & 1.2 \\
\hline New Injectable & 4.9 & 6.7 & $5.8^{*}$ & 2.9 & 3.5 & $3.2^{*}$ \\
\hline Injectable Check-up & 3.9 & 5.2 & 4.6 & 2.9 & 3.9 & $3.4^{*}$ \\
\hline Total & 35.0 & 42.7 & & 10.5 & 11.9 & \\
\hline
\end{tabular}

${ }^{*} p<.05$

Since the productivity of experimental and control RHCs was statistically different to begin with, a third analysis sought to assess if there was a significantly different rate of increase in the delivery of services between the groups and between the before and after periods. To conduct this analysis, we subtracted the number of services provided in each health center in the first pre-intervention month from the number of services provided in the first post-intervention month, the second pre-intervention month from the second post-intervention month, and the third pre-intervention month from the third post-intervention month for each service. We then conducted a t-test between groups and found a statistically significant higher rate of change in the experimental group than in the control group for all services, except for follow-up visits of injectable users. Table 3 shows the results of this analysis. 
Table 3

\section{Average Difference in the Delivery of Services between the Periods Before and After,by Experimental Group and Type of Service}

\begin{tabular}{|l|c|c|c|}
\hline \multirow{2}{*}{ SERVICE } & \multicolumn{2}{c|}{ GROUP } & \multirow{2}{*}{ SIGNIFICANCE } \\
\cline { 2 - 4 } & EXPERIMENTAL & CONTROL & \\
\hline Cytology & 1.61 & -0.11 & .05 \\
\hline IUD Insertions & 1.39 & -0.56 & .00 \\
\hline IUD Check-up & 1.61 & 0.39 & .01 \\
\hline New Injectables & 1.78 & 0.56 & .00 \\
\hline Injectables Check-up & 1.22 & 1.00 & .17 \\
\hline
\end{tabular}

A cost-effectiveness analysis of the intervention was also conducted. The total cost of the intervention was US $\$ 950$, including $\$ 150$ for the design, pre-test and printing of 25,000 brochures, $\$ 500$ for training and $\$ 500$ for supervision costs. Each brochure had a cost of 0.10 Lempiras ( $\$ 0.006$ cents). Taking all costs into consideration and dividing them by the number of services delivered (1,398 services) the promotion costs per service was $\$ 0.68$. Considering only the increase in the number of services, the overall increase in the experimental group was 7.7 monthly services per unit, compared with 0.9 in the control group. Considering six units and three months, the cost per additional service would be US\$7.8. However, this figure is excessive for four reasons. First, the cost is divided among six units, while in the expansion period of the strategy it would be divided among more than one hundred units. Second, the effect is considered for three months only, when the actual effect would presumably be for a longer period. Third, the project paid for meetings to train the nurse auxiliaries, whereas in the expansion period the training would take place during routine supervisory meetings and visits. Fourth, the study used 3,000 copies of the flyer (500 per unit), but 25,000 copies were printed. If we consider a total cost of $\$ 550$ (subtracting the training and the extra printing costs) and extrapolate the effects observed in the experiment to a six-month period and 100 units, we would have 4,080 additional users that would not have been obtained without the promotion, and the promotion costs would be US\$ 0.13 per additional user.

\section{UTILIZATION}

The brochure will be given to all the nurse auxiliaries of the $\mathrm{MOH}$ who have been trained to insert IUDs, give Depo-Provera injections and take Pap smear samples. It will also be distributed to NGO's that provide these services. The use of this kind of strategy for the promotion of other services will be suggested to the Maternal-Child Health and the Epidemiology Departments. 


\section{CONCLUSIONS AND RECOMMENDATIONS}

The intervention that was tested can be replicated on a larger scale and is both low-cost and effective in the short term, as shown by the increase in demand for the three new services by $11 \%$ after implementing the promotion strategy. The strategy was particularly effective in bringing in new IUD and Depo-Provera users, the long-term contraceptive options introduced to the rural communities where the intervention took place. Therefore, we recommend that the $\mathrm{MOH}$ conduct promotional activities in the communities where these services have recently been introduced.

\section{VIII.REFERENCES}

Secretaría de Salud de Honduras, Ashonplafa, CDC and USAID. 1997. Honduras:

Encuesta Nacional de Epidemiología y Salud Familiar 1996 [Honduras: National Epidemiology and Family Health Survey. 1996]. Tegucigalpa, Honduras.

Villanueva, Yanira L. Hernández, I. Mendoza and R. Lundgren. 1998. Expansión del Rol de las Auxiliares de Enfermería en el ofrecimiento de servicios de planificación familiar y en la toma de Citologías Vaginales [Expansion of the Role of Nurse Auxiliaries in the Delivery of Family Planning Services and Vaginal Citologies]. INOPAL III Final Report. Tegucigalpa, Honduras, Population Council

Secretaría de Salud de Honduras. Departamento de Salud Materno Infantil.1999.

Manual de Normas y Procedimientos de Atención Integral a la Mujer [Manual of Norms and Procedures for Women's Integral Health Care]. Secretaría de Salud, Tegucigalpa, Honduras, September 


\section{APPENDIX: PROMOTIONAL BROCHURE}
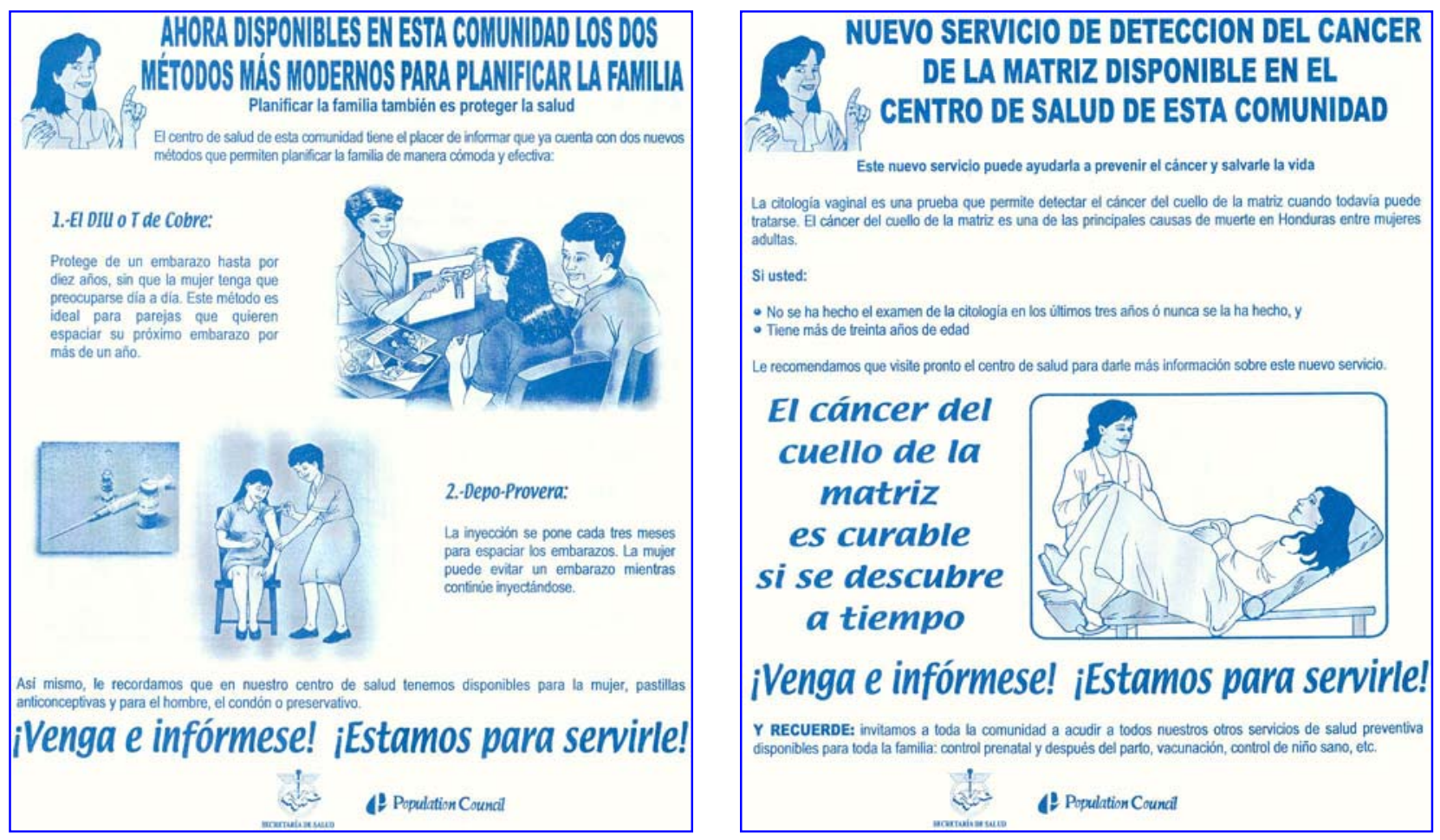